\title{
ADSORPTION OF POLLUTANT IONS FROM RESIDUAL AQUEOUS SOLUTIONS ONTO NANO-STRUCTURED CALCIUM SILICATE
}

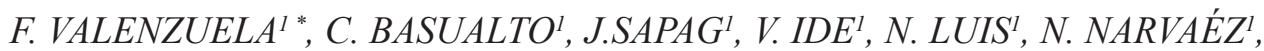 \\ S. YANEEZ ${ }^{1}$, T. BORRMANN \\ ${ }^{1}$ Laboratorio de Operaciones Unitarias, Facultad de Ciencias Químicas y Farmacéuticas Universidad de Chile, P.O. Box 233, Santiago 1, Chile
${ }^{2}$ School of Chemical and Physical Sciences, Victoria University of Wellington, P.O. Box 600, 6140 Wellington, New Zealand
}

(Received: October 29, 2012 - Accepted: January 15, 2013)

\begin{abstract}
The sorption of contaminant ions existing in residual aqueous solutions onto nano-structured calcium silicate has been studied. The sorbent was prepared by chemical reaction between a soluble solution of sodium silicate and calcium hydroxide. X-ray diffraction analysis showed the amorphous character of the obtained calcium silicate, although patterns associated to wollastonite, $\mathrm{CaSiO}_{3}$, and larnyta-syn, $\mathrm{Ca}_{2} \mathrm{SiO}_{4}$ were detected. The particle mean size was approximate 0.5 to $1.0 \mu \mathrm{m}$ having an average BET surface area of $333.0 \mathrm{~m}^{2} / \mathrm{g}$ and a mean pore diameter variable between $15.8-23.6 \mathrm{~nm}$. The nano-structured calcium silicates were contacted with industrial residual aqueous solutions containing, among others, $\mathrm{Cu}(\mathrm{II}), \mathrm{Zn}(\mathrm{II}), \mathrm{Cd}(\mathrm{II})$ and the anions $\mathrm{PO}_{4}{ }^{3-}, \mathrm{SO}_{4}{ }^{-}$and $\mathrm{CrO}{ }_{4}{ }^{-}$, being copper (II) and phosphate the ions that were most easily and quantitatively adsorbed. The results of equilibrium experiments showed that the Redlich-Peterson adsorption isotherm model explained the experimental results for some metal ions. The experimental kinetics followed a pseudo-second-order kinetics model for $\mathrm{Cu}(\mathrm{II})$ and $\mathrm{Zn}$ (II) sorption.
\end{abstract}

Keywords: Adsorption, Pollutant ions, Nanostructured calcium silicate, Aqueous solutions

\section{INTRODUCTION}

The impact of liquid industrial and mining residues is quite troublesome, affecting the life quality of the population and causing great damage to the environment. The adequate management of such residues presents a challenge of increasing complexity. As government guidelines are becoming very strict in respect to the regulation and treatment of these industrial and mining liquid residues, it is necessary to search technological alternatives to decrease the volume of effluents and to reduce the amount of contaminants in them. Typically industrial wastewaters are acidic containing variable amounts of dissolved metals and anions at levels that can surpass legal regulations and also present a substantial loss in valuable compounds. This means that pollutants must be removed due their toxicity and that resources need to be recovered due to economical considerations ${ }^{1}$. The main challenge in the recovery or removal of compounds from liquid wastes is to do so while using simple and practical methods.

Many methodologies have been tested to treat industrial and mining residual waters, most of which focus on the uptake of metallic ions and only investigate the removal of anions to a lesser degree. The principles that govern the conventional separation processes as well as their practical technology have been described in the technical literature, and it can be stated that all of them have some deficiencies that limit their applicability under many operational and economic considerations. For example, chemical precipitation generates solids that are not always stable; complete or partial re-dissolution occur easily resulting in the formation of large amounts of sludge, which is difficult to process ${ }^{2}$. The use of solid ion-exchange resins is complex and requires regeneration of the loaded resins after sorption of pollutants, which is not always quantitative and is negatively affected by the presence of fine suspended solid ${ }^{3,4)}$. Removal of some metallic cations by biosorption appears to be interesting, but is limited to removing only a small amounts of metals because of reduced loading capacities ${ }^{5}$.

Undoubtedly solvent extraction methods (SX) are by far the most important industrial tool for separating and recovering metallic ions from aqueous solutions, as they are easily applied on large-scale in continuous processes. However, in the practical operation of SX appear many difficulties such as the loss of extractant due to several reasons including entrainment and crud formation as well as due to solubility of organic solvent in the metal-containing aqueous feed phase ${ }^{6}$. The use of a permeation process through liquid membrane (LM) contactors was derived from SX technology. Permeation processes were developed in 1968 by Li et al. and use the same extractants as SX? ${ }^{7}$. Two liquid membrane processes have been used in hydrometallurgy and in wastewater treatment: a) Solid supported liquid membranes are produced by dispersing or impregnating the pores of an inert solid support with an extractant. The practical application of such systems is often limited by their surface area ${ }^{8)}$ b) Surfactant liquid membranes correspond to a double layer water-in-oil emulsion, which must be stabilized by using a surfactant and in some cases are not easily reproducible ${ }^{9}$.

The development of natural and synthetic sorbents that make the removal of metallic ions and other species from aqueous solutions feasible must be considered one of the most interesting and promising technological goals in the field of separation processes. During the past years a number of sorbents have been used successfully to treat industrial and mining wastewaters, natural surface and ground waters as well as acidic mine drainages (AMD), which are highly polluted with heavy metals ions and anions ${ }^{10,11}$. Examples of natural and synthetic adsorbents are among others activated carbon ${ }^{12)}$, zeolites ${ }^{13,14}$, various clays ${ }^{15)}$, kaolinites ${ }^{16)}$, metal oxides ${ }^{17)}$, and organic compounds like chitosan $^{18)}$, sawdust ${ }^{19)}$, and allophones ${ }^{20)}$, solvent impregnated resins (SIR) ${ }^{21)}$ and polymeric matrices that encapsulate organic extractants in their porous structure ${ }^{22,23)}$. Many of the adsorbents have quite distinct and different properties and adsorbent activity, which make them interesting to study. However, the obtainment of the absorbents by extraction from nature or their synthesis over several sequential stages is usually expensive, making their employ for most of industrial applications unpractical and uneconomical. During the last few years many researchers have developed nano-structured and nano-particulate compounds and have engaged these compounds in the field of water and wastewater treatment ${ }^{24,25}$. For example, Huang et al studied the rapid removal of heavy metal cations and anions from aqueous solutions by an amino-functionalized magnetic nano-adsorbent ${ }^{26}$.

In this work we have prepared nano-structured calcium silicates to be used as inorganic sorbents to treat mining and chemical industrial waste solutions contaminated, among other substances, with $\mathrm{Cu}(\mathrm{II}), \mathrm{Zn}(\mathrm{II}), \mathrm{Cd}(\mathrm{II})$ and the anions $\mathrm{SO}_{4}=, \mathrm{PO}_{4}^{3-}$ and $\mathrm{CrO}_{4}=$, at higher concentrations than those allowed by current Chilean regulations related to emission and discharge of liquid industrial wastes ${ }^{27}$. The nano-structured-materials are intended to have the capacity for removing both anions and cations simultaneously. The uptake of the ions is made feasible by the specific surface area of the silicates, averaging values over $300 \mathrm{~m}^{2} / \mathrm{g}$, and due to the existence of functional groups on their surfaces such as $\mathrm{Ca}(\mathrm{II})$ ions and hydroxyl groups (silanol), which can act as binding or nucleation sites on the silicate surface. The nano-structured calcium silicate material proprietary to one of the authors of this paper can be easily synthesized using a low-cost process ${ }^{28}$.

\section{EXPERIMENTAL PROCEDURE}

The synthesis of nano-structured calcium silicate can be conducted using several routes of preparation. In this study calcium silicate was synthesized by precipitation as a result of the room temperature chemical reaction between liquid $\mathrm{Na}_{2} \mathrm{SiO}_{3}$ and $\mathrm{Ca}(\mathrm{OH})_{2}$ at a $\mathrm{pH}$-value of 12.3 , following a process in two steps. In the first step a suspension of $\mathrm{Ca}(\mathrm{OH})_{2}$ in water was dosed with $\mathrm{HCl}$ $33 \% \mathrm{w} / \mathrm{w}$ to give a slurry with a $\mathrm{pH}$-value of 12 to 12.5 , varying the stirring 
velocity in a range between 425 to $1000 \mathrm{~min}^{-1}$. In a second step, a sodium silicate solution containing $28.5 \% \mathrm{w} / \mathrm{w} \mathrm{SiO}_{2}$ was diluted with water resulting in a $0.32 \% \mathrm{w} / \mathrm{w} \mathrm{SiO}_{2}$ solution. Then, this solution was vigorously mixed with the previously prepared $\mathrm{Ca}(\mathrm{OH})_{2}$, suspension in a big plastic reactor, varying the stirring velocity between 1000 and $6000 \mathrm{~min}^{-1}$, immediately forming a precipitate, nano-structured calcium silicates containing an average value of 35 $\mathrm{g} \mathrm{SiO}_{2} / \mathrm{kg}$ of formed solid. The formed slurry was aged for 20 minutes, allowed to settle for 13 hours, before the obtained solids were recovered by vacuum filtration. Afterwards, the filter cake was washed with water and ethanol in order to disperse the nano-structured particles and lower the surface tension of still wet solid. The solid was dried at $383 \mathrm{~K}$ during two days. Treatment with ethanol is necessary because during the drying of silicate, which presents a high surface area, is generated a great liquid-air interface that causes a high surface tension collapsing the structure of the material reducing its pore volume and surface area. In order to characterize the synthesized compounds, the nano-structured calcium silicates were observed by scanning electron microscopy (SEM) using a JEOL JSM-25SII instrument. The mean particle size was determined using a Malvern Mastersizer Hydro 2000 MU apparatus. Furthermore, porosimetry analyses including the determination of the specific surface area were conducted using a $\mathrm{N}_{2}$ sorptometer in a Micromeritics ASAP 2010 porosimeter at $20^{\circ} \mathrm{C}$ and $1 \mathrm{~atm}$. Oil adsorption tests were carried out using linseed oil in a spatula rubout method ASTM D281. To determine if the nano-structured calcium silicates present a crystalline or amorphous structure, samples of the prepared solids were analysed using a Bruker D8 Advance X-ray powder diffractometer which poses a LynxEye lineal detector. Measurements were carried out at a $\lambda=1.5406 \AA$ correspondent to a copper anode having a power of $40 \mathrm{KV} / 30 \mathrm{~mA}$.

Batch equilibrium sorption tests were conducted at $303 \mathrm{~K}$ in a Polyscience orbital-shaker apparatus by mixing a variable amount of nano-structured calcium silicate and different volumes of two industrial waste solutions: a residual stream from a Chilean copper mine and a chemical industrial wastewater; the compositions of these are listed in Table 1. Both solutions were weakly acidic containing an important amount of total suspended solids.

The batch experiments were conducted over sufficient time to reach equilibrium. During the experiments, samples of the solution were collected at determined intervals and filtered through a $0.45 \mu \mathrm{m}$ nitrocellulose Millipore membrane, before their $\mathrm{pH}$-value and the metallic ions content by atomic absorption spectrophotometry on a Perkin Elmer 3110 instrument, including chromium total content was measured. The quantity of metal adsorbed was determined by the difference between the concentrations of metal in the initial aqueous feed phase and that in the raffinate solutions. At the end of the experimental tests, the nano-structured calcium silicates were separated from the resulting aqueous solution by filtration. $\mathrm{The} \mathrm{SO}_{4}{ }^{-}$ion content was determined using a standard barium sulphate method ${ }^{49}$ ) and $\mathrm{PO}_{4}^{3-}$ ion concentration was measured using the vanadate-molybdate-phosphoric UVspectroscopy method ${ }^{30}$.

Table 1: Main composition of mining and chemical industrial residual solutions.

\begin{tabular}{|c|c|c|}
\hline Aqueous Residual Solutions & Ionic species & Concentration (mg/L) \\
\hline Mining & $\mathrm{Cu}(\mathrm{II})$ & $90-300$ \\
\hline $\mathrm{pH}: 2.8-4.2$ & $\mathrm{Zn}(\mathrm{II})$ & $30-80$ \\
\hline & $\mathrm{SO}_{4}^{2-}$ & $500-4000$ \\
\hline Chemical Industry & $\mathrm{Cd}(\mathrm{II})$ & $5-80$ \\
\hline $\mathrm{pH}: 4-6$ & $\mathrm{Cr}(\mathrm{VI})$ & $10-50$ \\
\hline & $\mathrm{PO}_{4}{ }^{3-}$ & $20-200$ \\
\hline
\end{tabular}

\section{RESULTS AND DISCUSSION}

\section{Synthesis and characterization}

The chemical reaction between $\mathrm{Ca}(\mathrm{OH})_{2}$ and $\mathrm{Na}_{2} \mathrm{SiO}_{3}$ was quite fast generating a thixotropic precipitate, which due to its high water content, porosity and particle size was not always easy to recover. Effectively the reaction of $\mathrm{Ca}$ (II) ions with soluble silicate as $\mathrm{Na}_{2} \mathrm{SiO}_{3}$ resulted in the precipitation of calcium silicate, an insoluble solid, where $\mathrm{Ca}$ (II) appeared to be strongly bound to a silicate backbone. The extent of the reaction and the particle size of the solid formed depended strongly on the $\mathrm{pH}$ of the reaction mixture, the proportions and concentration of calcium and silicate ions and the intensity of the stirring employed during the process. Intensive stirring in basic medium produced a quite homogeneous but colloidal and amorphous insoluble calcium silicate. The higher the stirring velocity and the lower the concentrations during the reaction the smaller should be the size of the resultant calcium silicate particles and the larger and more accessible should be their surface area comprising of micro-pores and meso-pores. However, due to the thixotropic nature of calcium silicate agglomeration of particles was known to occur.

Several batches of synthesis of calcium silicate were conducted following the procedure indicated in the experimental section, varying the stirring velocity of the first step of the process, where $\mathrm{Ca}(\mathrm{OH})_{2}$ was mixed with a $33 \% \mathrm{w} / \mathrm{w} \mathrm{HCl}$ solution in a range between 425 to $1000 \mathrm{~min}^{-1}$. In the second step, the stirring velocity between this phase and the $\mathrm{Na}_{2} \mathrm{SiO}_{3}$ solution was varied between 1000 $\mathrm{min}^{-1}$ and $6000 \mathrm{~min}^{-1}$. No significant effect of increasing the stirring velocity of the partial dissolution of $\mathrm{Ca}(\mathrm{OH})_{2}$ in $\mathrm{HCl}$ on the production of calcium silicate was observed. Furthermore, the influence of the stirring intensity in this step had no influence on the particle size of the generated solids, all of them being in the same particle size range. However, the contact of $\mathrm{HCl}$ solution with the alkali would produce later better reaction and integration of the $\mathrm{Ca}(\mathrm{OH})_{2}$ with the $\mathrm{Na}_{2} \mathrm{SiO}_{3}$ solution. In contrast, the stirring speed of the second step where the calcium source and $\mathrm{Na}_{2} \mathrm{SiO}_{3}$ were mixed - would have influence on the production of calcium silicate particles improving the production of these solids, results that must be confirmed with further experiments. However, this variable affected the particle size of the obtained solid generating calcium silicate particles of smaller size when a higher stirring speed was employed during this second step.

In all these experiments the limiting reagent was the $\mathrm{Ca}(\mathrm{OH})_{2}$ in order to assure that all solid formed in the synthesis is calcium silicate precipitate and no excess of lime could be sorbed on the silicate surface, leading to a miscalculation of yield. It is not easy to establish a chemical reaction that assumes the formation of calcium silicate due to the great variety of silicate species possible to be formed and to the proportion of hydroxyl and silanol groups that silicate would contain. Even the synthesized calcium silicate as an amorphous substance does not present a defined chemical structure only a model as is shown in the scheme of Figure 1, based on X-ray fluorescence spectrometry, ${ }^{29} \mathrm{Si} \mathrm{NMR}$, solid state NMR and others analytical methodologies. Borrmann et al have assumed the formula $\mathrm{Ca}_{0.8} \mathrm{SiO}_{2.4} 2 \mathrm{H}_{2} \mathrm{O}$, which corresponded to approximately $24 \%(\mathrm{w} / \mathrm{w}) \mathrm{Ca}, 21 \%(\mathrm{w} / \mathrm{w}) \mathrm{Si}, 35 \%$ (w/w) $\mathrm{O}, 20 \%(\mathrm{w} / \mathrm{w})$ $\mathrm{H}_{2} \mathrm{O}$, confirming the presence of hydroxil groups and adsorbed water on the surface of the material ${ }^{31,32)}$.

Figure 2 shows SEM micrographs of the synthesized nano-structured calcium silicates. It was observed that the synthesized material corresponded to an amorphous without a defined structure. Particles had a mean particle size averaging 0.5 to $1.0 \mu \mathrm{m}$ with particles forming larger agglomerates. This particle size was corroborated using a Malvern Mastersizer apparatus. For the examined range, the higher the stirring speed in the final step of synthesis the smaller the particle sizes of the obtained solid.

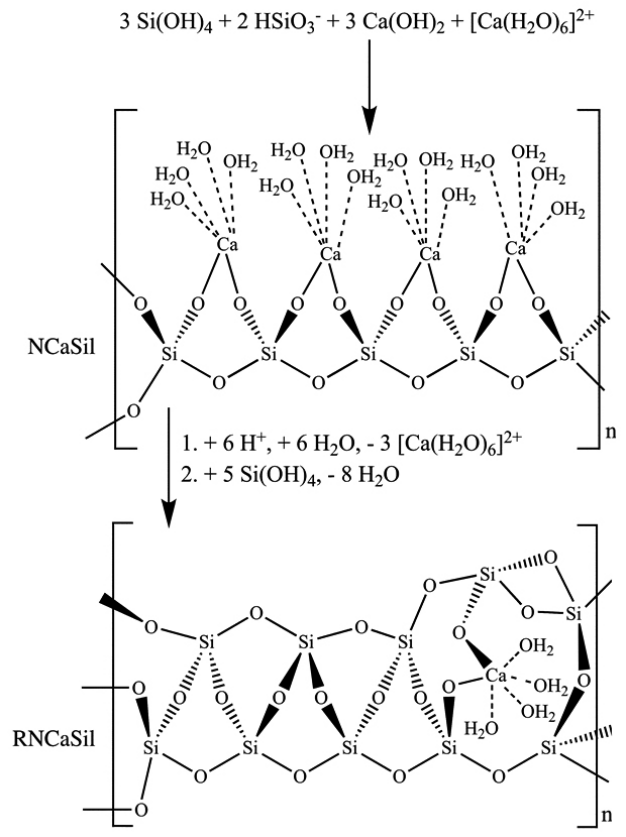

Figure 1: Scheme of nano-structured calcium silicate form. 

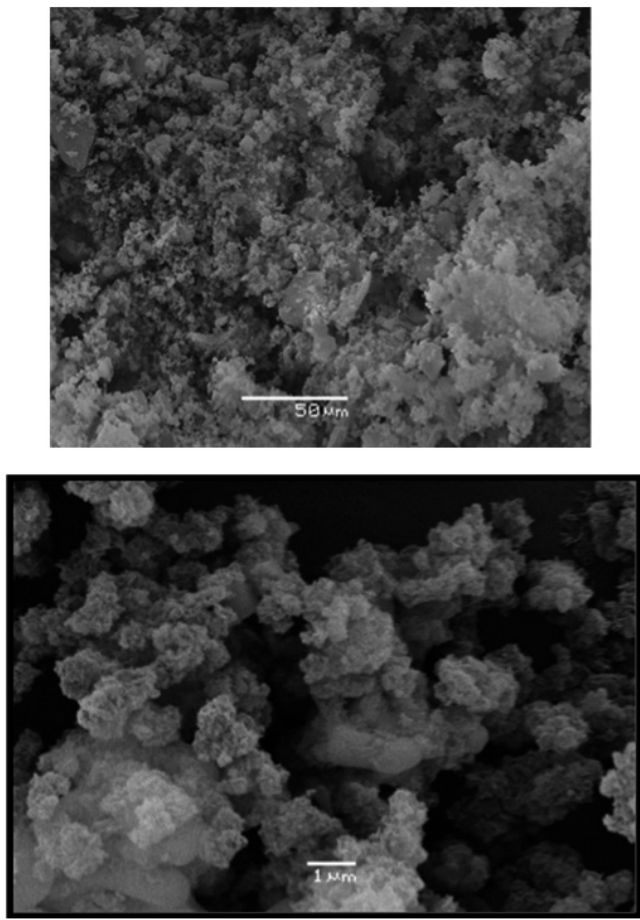

Figure 2: SEM micrographs of nano-structured calcium silicate.

Details of nano-structured calcium silicate have been described in former communications by Borrmann et al, author of this contribution, using ${ }^{29} \mathrm{Si}-\mathrm{NMR}$ spectroscopy and X-ray photoelectron spectroscopy (XPS) analysis proposing a silicate backbone shown in Figure 1 with plates of a thickness around of 10 $\mathrm{nm}$. It would comprise of silicate tetrahedral with $\mathrm{Ca}$ (II) ions and silanol groups on the surface forming a structure associated with wollastonite, $\mathrm{CaSiO}_{3}$, the calcium silicate mineral species which contains $\mathrm{SiO}_{3}{ }^{2}$-silicates species in which $\mathrm{Ca}(\mathrm{II})$ ions and the silanol groups would act as probable binding sites. Cairns et al have proposed that the calcium silicate would contain $1.5 \%$ of hydroxil groups meaning that approximately $8 \%$ of silicon atoms present are silanol groups allowing metallic ions like $\mathrm{Cu}(\mathrm{II})$ and $\mathrm{Zn}(\mathrm{II})$ to form the respective hydroxides on the surface of the silicates, which would act as nucleation site ${ }^{33)}$. Measurements of porosimetry analysis using the $\mathrm{N}_{2}$ sorptometer, indicated for the obtained nano-structured compounds an average surface area of $333.0 \mathrm{~m}^{2} / \mathrm{g}$, value much higher than the surface area shown by other sorbents prepared in our laboratory ${ }^{22,23,34)}$. The mean pore diameter varied between 15.8-23.6 $\mathrm{nm}$ and the pore volume between $0.7853-1.5441 \mathrm{~cm}^{3} / \mathrm{g}$ for calcium silicates synthesized at $6000 \mathrm{~min}^{-1}$ and $2000 \mathrm{~min}^{-1}$, respectively. These values confirm that the higher the stirring speed during the second step of the synthesis of sorbents the finer the structural features of the prepared solids. Furthermore, the linseed oil adsorption tests confirmed the huge sorption capacity of the synthesized calcium silicates being measured an average of $1.2 \mathrm{~g}$ oil adsorbed per $1.0 \mathrm{~g}$ of silicate.

$\mathrm{X}$-ray diffraction analysis indicated that the prepared compounds are basically amorphous or at least polycrystalline. However, elements of patterns associated with wollastonite, $\mathrm{CaSiO}_{3}$, and larnyta-syn, $\mathrm{Ca}_{2} \mathrm{SiO}_{4}$, were observed confirming the synthesis of a calcium silicate, Figure 3. The silicate material also displayed the diffraction patterns of calcite $\left(\mathrm{CaCO}_{3}\right)$ and halite $(\mathrm{NaCl})$, both compounds were impurities associated with the source materials, calcite as found in $\mathrm{Ca}(\mathrm{OH})_{2}, \mathrm{NaCl}$ from $\mathrm{Na}_{2} \mathrm{SiO}_{3}$ and $\mathrm{HCl}$ used in the synthesis. Although natural silicates are crystalline, like natural wollastonite, the solids prepared in this study appeared amorphous, probably because they were prepared by precipitation from aqueous solutions. Soluble silicates found in solutions comprise silicate ions of different size, most of them polymerized, which are not able to organise themselves in a crystal form resulting in a colloidal solid.

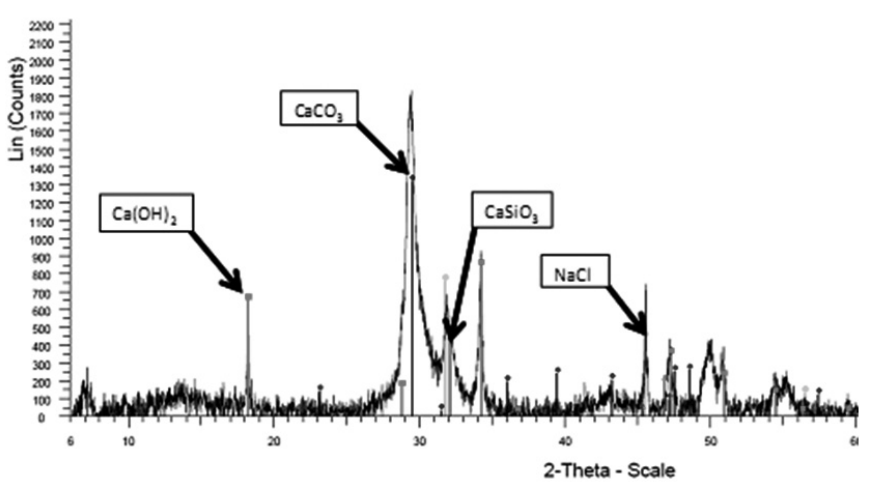

Figure 3: X-ray diffraction analysis of synthesized nano-structured calcium silicate.

\section{Adsorption experiments}

Sorption experiments were carried out with the purpose to measure the capability of these nano-structured calcium silicates to uptake diverse metallic ions and some anions found in many residual industrial and mining wastewaters. Most of the experiments were conducted using aqueous solutions whose initial metals concentrations are those described in Table 1. However, in order to establish the maximum metal sorption capacity of the nanostructured calcium silicates, some experiments were carried out using feed aqueous solutions in which the content of metals in them was increased up to $5 \mathrm{~g} / \mathrm{L}$. The results are presented in Figure 4. This plot shows the dependence of adsorption of several metallic ions onto the synthesized compounds on the initial concentration of these ions in aqueous solutions at an initial $\mathrm{pH}$-value of 4.0. Figure 4 shows that a high sorption is reached for $\mathrm{Cu}(\mathrm{II}), \mathrm{Zn}(\mathrm{II})$ and $\mathrm{Cd}(\mathrm{II})$, all of them measured 10 minutes after the contact. Adsorption of $\mathrm{Cu}(\mathrm{II})$ and $\mathrm{Zn}$ (II) was determined using the mining residual stream and $\mathrm{Cd}$ (II) uptake was measured using the chemical industry wastewater. Although the composition of both solutions are different, it is possible to indicate that the high sorption measured for these metallic ions, which exist as cationic species in solution, was related to the formation of insoluble species, very likely hydroxides. From this figure the maximum metal sorption capacity can be calculated for each ion as follows: $0.75-0.88 \mathrm{mg} \mathrm{Cu}(\mathrm{II}) / \mathrm{mg}$ calcium silicate, $0.25-0.32 \mathrm{mg} \mathrm{Zn}(\mathrm{II}) / \mathrm{mg}$ calcium silicate and $0.25-0.33 \mathrm{mg} \mathrm{Cd}(\mathrm{II}) / \mathrm{mg}$ calcium silicate. These values are much higher than those measured for other natural and synthetic sorbents ${ }^{35,36}$.

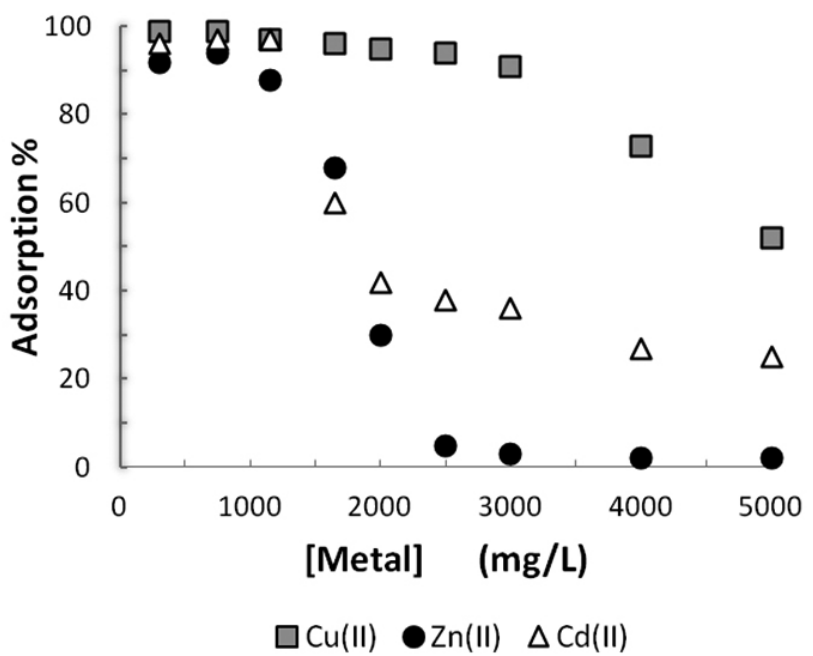

Figure 4: Adsorption of $\mathrm{Cu}(\mathrm{II}), \mathrm{Zn}(\mathrm{II})$ and $\mathrm{Cd}(\mathrm{II})$ onto nano-structured calcium silicate.

In Figure 5 are shown the results observed for the sorption of the anions $\mathrm{PO}_{4}^{3-}, \mathrm{SO}_{4}{ }^{-}$and $\mathrm{CrO}_{4}{ }^{-}$used in the test solutions employing as sorbent the same sample of nano-structured calcium silicate used for the sorption of the cations. Uptake of $\mathrm{PO}_{4}{ }^{3-}$ and $\mathrm{CrO}_{4}{ }^{=}$was measured using samples of the chemical industry 
residual solution and sorption of $\mathrm{SO}_{4}{ }^{-}$from the mining effluent. Sorption of $\mathrm{PO}_{4}{ }^{3-}$ was fairly high, although, showing a lower sorption kinetics compared to the metal cation adsorption. $\mathrm{SO}_{4}{ }^{-}$was also adsorbed, until a maximum uptake point was reached for this anion. $\mathrm{Cr}(\mathrm{VI})$ was not sorbed at all probably because this ion is present in aqueous solution as anionic species such $\mathrm{CrO}_{4}^{2-}, \mathrm{HCrO}_{4}^{-}$ or $\mathrm{Cr}_{2} \mathrm{O}_{7}{ }_{7}^{2-}$ that do not tend to form insoluble salts with $\mathrm{Ca}(\mathrm{II})$ ions. Therefore, $\mathrm{Cr}(\mathrm{VI})$ was not retained on the surface of calcium silicate. In turn, $\mathrm{SO}_{4}{ }^{-}$and $\mathrm{PO}_{4}^{3-}$ form insoluble or only slightly soluble calcium salts with $\mathrm{Ca}(\mathrm{II})$ ions, feasible to be adsorbed on the surface of nano-structured silicates. However, the sorption of $\mathrm{PO}_{4}{ }^{3-}$ was higher than that of $\mathrm{SO}_{4}{ }^{-}$in agreement with the lower solubility of $\mathrm{Ca}_{3}\left(\mathrm{PO}_{4}\right)_{2}$ compared to $\mathrm{CaSO}_{4}$. Probably a high proportion of calcium silicate is required to uptake higher contents of $\mathrm{SO}_{4}=$ from aqueous solution.

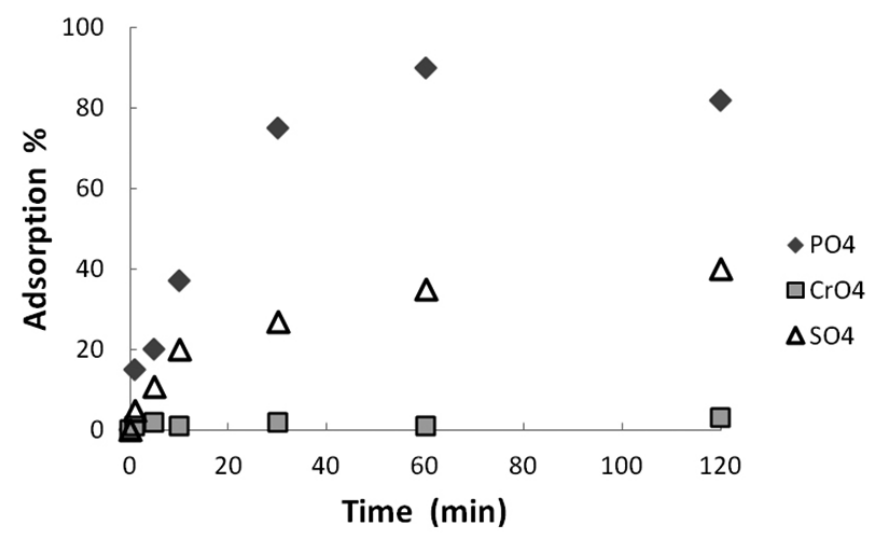

Figure 5: Adsorption of anions onto nano-structured calcium silicate.

It is well known that metallic ions such as $\mathrm{Cu}(\mathrm{II}), \mathrm{Zn}(\mathrm{II})$ and $\mathrm{Cd}(\mathrm{II})$ tend to easily form insoluble hydroxides under basic conditions. However, their removal by precipitation only with lime is far from an ideal solution when their content in solution is high enough to consider them pollutants. Often precipitation of these metals with lime or similar hydroxides is incomplete. The generated precipitates are colloidal and difficult to separate through sedimentation and conventional filtration; most of them tend to re-dissolve as results of minor $\mathrm{pH}$ changes. In light of this, it was important to verify whether the precipitation of these cationic ions with the aid of these nano-structured calcium silicates could be improved. It was clearly observed that, although the precipitation of metal cations with silicates proceeded slower than with $\mathrm{NaOH}$ it was comparable in speed to that with lime. A more important point though is that in the presence of nano-structured calcium silicate the extent of precipitation reached was significantly higher than that observed with only lime being used. The degree of removal of $\mathrm{Cu}(\mathrm{II}), \mathrm{Zn}(\mathrm{II})$ and $\mathrm{Cd}(\mathrm{II})$ ions was higher and more stable precipitates were formed using the nano-structured calcium silicates prepared in this study. It is reasonable to think that silicates kept the $\mathrm{pH}$-value in a more basic region acting as a buffer. Thereby they ensured a good precipitation of metallic ions. Furthermore, the precipitates generated in this case were of a more granular nature, meaning that they could be decanted or separated by filtration more easily than the precipitates obtained using lime or $\mathrm{NaOH}$. This fact suggested that the metal removal from aqueous solutions would be a cation exchange between the metals to remove and the calcium ions associated with the silicate structure.

Batch type equilibrium experiments were carried out at $30^{\circ} \mathrm{C}$ to determine the relationship between the quantity of metal adsorbed by nano-structured calcium silicate and the experimental conditions. In these experiments as in the kinetics experimental runs were used samples of the same waste solutions which were previously filtrated using the Millipore membrane to avoid the presence of fine solid particles. The results for $\mathrm{Cu}(\mathrm{II})$ sorption from the mining effluent are shown in Figure 6. The amount of metal adsorbed was plotted against the equilibrium metal concentration and the resulting data modelled using the Redlich-Peterson isotherm. The Redlich-Peterson isotherm is a hybrid sorption model employed to analyse experimental data that does not fit well with other theoretical (Langmuir) and empirical (Freundlich) models. It incorporates characteristics of both equations:

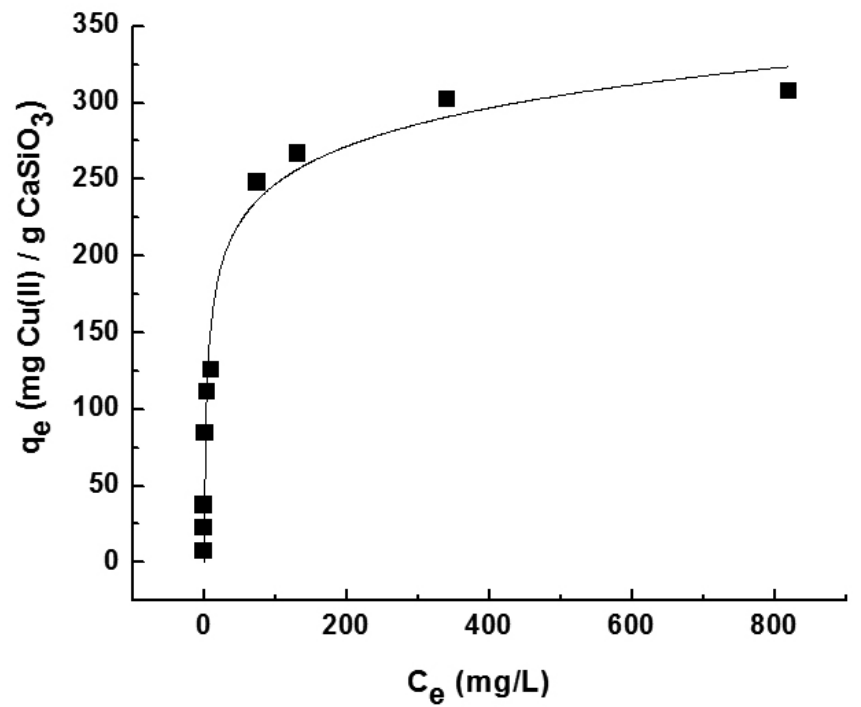

Figure 6: Adsorption equilibrium of $\mathrm{Cu}(\mathrm{II})$ with nano-structured calcium silicate.

$$
q_{e}=\frac{A \cdot C_{e}}{1+K_{R-P} C_{e}^{g_{R-P}}}
$$

where $q_{e}$ denotes the amount in $\mathrm{mmol} \mathrm{g}^{-1}$ adsorbed at equilibrium, and $C_{e}$ is the metal concentration in $\mathrm{mmol} \mathrm{L}^{-1}$ that remains in solution after the extraction. $A(L / g)$ and $K_{R-P}(L / m m o l)^{g}$ are Redlich-Peterson model constants. $g_{R-P}[-]$ corresponds to the model exponent, the value of which is theoretically limited between 0 (where it behaves as in Henry's law) and 1 (where it behaves as in the Langmuir isotherm). All of the parameters were evaluated by non-linear regression using the Lavenberg-Marquardt iteration routine ${ }^{37}$. The model gave the following values for the parameters and constants of the equilibrium sorption using nano-structured calcium silicate: $0.47(\mathrm{~L} / \mathrm{mmol})^{\mathrm{g}}$ for $K_{R-P}, 71.03$ $(L / g)$ for $A$ and 0.886 for $g_{R-P}[-] . R^{2}$ values of 0.9730 indicated that the RedlichPeterson isotherm model fit the experimental results well. Similar results were obtained for the other metal ions.

Kinetic experiments were carried out during $2 \mathrm{~h}$ time spans, enough time to reach equilibrium, using a sample of the mining effluent containing $90 \mathrm{mg} / \mathrm{L}$ $\mathrm{Cu}$ (II) and $80 \mathrm{mg} / \mathrm{L}$ of $\mathrm{Zn}(\mathrm{II})$ at an initial $\mathrm{pH}$-value of 4.0. In Figure 7 are presented the kinetics results for the sorption of $\mathrm{Cu}$ (II) and $\mathrm{Zn}$ (II) onto a sample of calcium silicate obtained a $6000 \mathrm{rpm}$. Both metallic ions were rapidly and completely sorbed within few minutes. Results of this work were analysed by applying a pseudo-second order kinetic model. This model is based on the sorption capacity of the sorbent. It is feasible to apply the model for high concentrations of adsorbate on the surface of the calcium silicate: ${ }^{38)}$

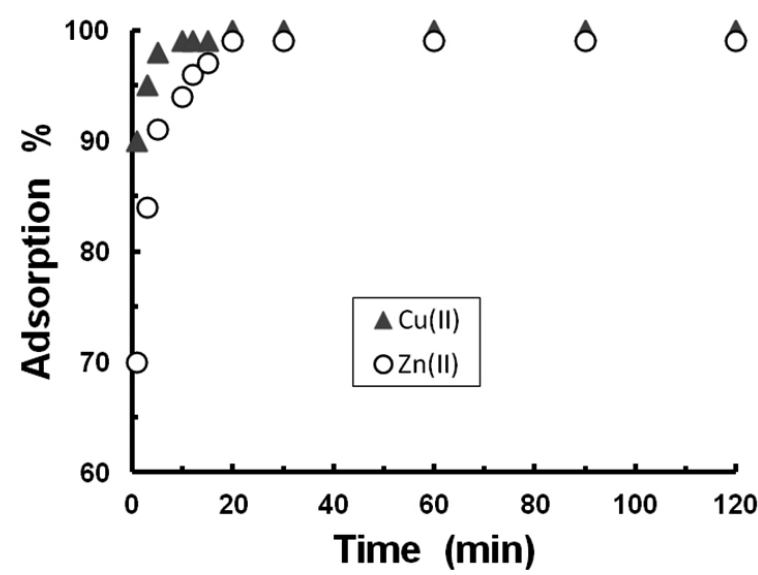

Figure 7: Sorption kinetics of $\mathrm{Cu}$ (II) and $\mathrm{Zn}$ (II) onto nano-structured calcium silicate. 


$$
q_{t}=\frac{q_{e}^{2} \cdot k_{2} \cdot t}{1+q_{e} \cdot k_{2} \cdot t}
$$

where $q$ is the molarity of the metal adsorbed onto the silicate at any time $t\left(\mathrm{mmol}_{M C}{ }^{-1}\right), k_{2}$ the pseudo-second order reaction rate constant $\left(g_{M C} / \mathrm{mmol} / \mathrm{sec}\right)$ and $q_{c}$ is as previously defined.

This pseudo-second-order kinetic model applied to the experimental results for the adsorption of $\mathrm{Cu}(\mathrm{II})$ and $\mathrm{Zn}$ (II) onto nano-structured calcium silicate is shown in Figure 8; a linear fit of data was attempted. The experimental values have been plotted according to equation (2). Furthermore, the rate constants, $k_{2}$, the equilibrium sorption capacity, $q$, and the coefficient of determination, $\mathrm{R}^{2}$, obtained by linear regression for the adsorption of both metals are listed in Table 2. In Figure 8 is observed a good agreement of the experimental data with the calculated using equation (2) for the pseudo-second order kinetic model.

Table 2: Parameters of kinetics model applied to $\mathrm{Cu}(\mathrm{II})$ and $\mathrm{Zn}(\mathrm{II})$ adsorption onto nano- structured calcium silicate.

\begin{tabular}{|c|c|c|c|c|c|}
\hline \multicolumn{3}{|c|}{$\mathrm{Cu}(\mathrm{II})$} & \multicolumn{3}{|c|}{$\mathrm{Zn}$ (II) } \\
\hline $\begin{array}{c}\boldsymbol{q}_{e} \\
{[\mathrm{mg} / \mathrm{g}]}\end{array}$ & $\begin{array}{c}\boldsymbol{k}_{2} \\
{[\mathrm{~g} / \mathrm{mg} . \mathrm{min}]}\end{array}$ & $\boldsymbol{R}^{2}$ & $\begin{array}{c}\boldsymbol{q}_{e} \\
{[\mathrm{mg} / \mathrm{g}]}\end{array}$ & $\begin{array}{c}\boldsymbol{k} \\
{[\mathrm{g} /}\end{array}$ & $\boldsymbol{R}^{2}$ \\
\hline $\mathbf{m g . m i n}]$ & \\
\hline 22.48 & 1.41 & $\mathbf{0 . 9 9 9 8}$ & $\mathbf{2 0 . 0 3}$ & $\mathbf{0 . 1 5}$ & $\mathbf{0 . 9 9 9 7}$ \\
\hline
\end{tabular}

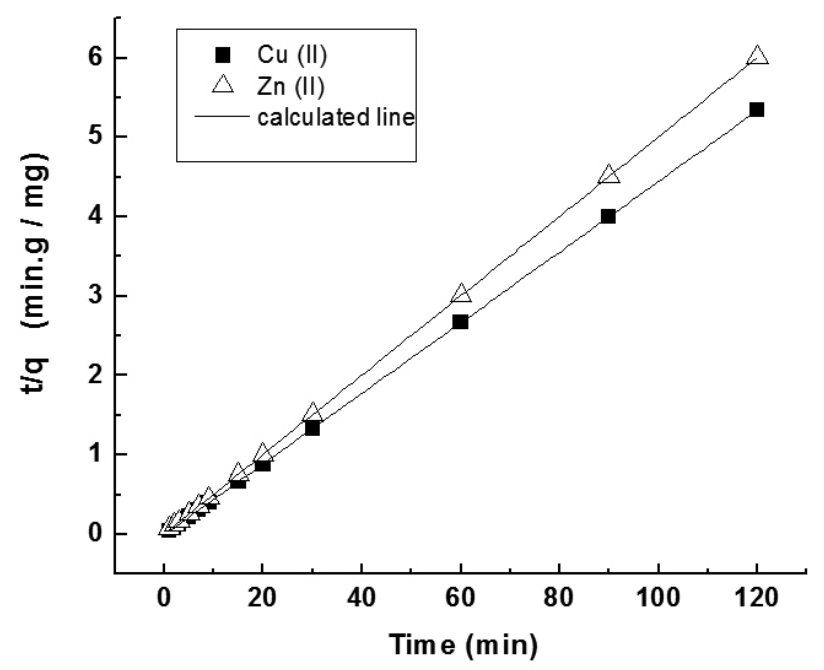

Figure 8: Pseudo-second-order kinetics model of $\mathrm{Cu}$ and $\mathrm{Zn}$ sorption onto nano-structured calcium silicate.

\section{CONCLUSIONS}

In this work, the adsorption of pollutants, such as $\mathrm{Cu}(\mathrm{II}), \mathrm{Zn}(\mathrm{II}), \mathrm{Cd}(\mathrm{II})$, $\mathrm{PO}_{4}^{3-}, \mathrm{SO}_{4}{ }^{=}$and $\mathrm{CrO}_{4}=$ ions, onto nano-structured calcium silicates from residual aqueous solutions was investigated using a batch system. The sorbent was easily synthesized by chemical reaction between $\mathrm{Ca}(\mathrm{OH})_{2}$ and a solution of $\mathrm{Na}_{2} \mathrm{SiO}_{3}$ being obtained as insoluble and amorphous precipitate. A higher stirring intensity during the synthesis generated a finer structure of the prepared solids. The calcium silicate was characterized using different methodologies confirming its amorphous character. The silicate did not appear to have a defined chemical structure. It was shown to have particles whose mean size was 0.5 to $1.0 \mu \mathrm{m}$ having an average surface area of $333.0 \mathrm{~m}^{2} / \mathrm{g}$. The pores on its surface were very fine with a mean pore diameter that varied between 15.8$23.6 \mathrm{~nm}$ and a pore volume between $0.7853-1.5441 \mathrm{~cm}^{3} / \mathrm{g}$. X-ray diffraction analysis confirmed the amorphous or polycrystalline character of prepared compounds; patterns associated with wollastonite, $\mathrm{CaSiO}_{3}$, and larnyta-syn, $\mathrm{Ca}_{2} \mathrm{SiO}_{4}$ were detected.

In uptake studies $\mathrm{Cu}(\mathrm{II})$ ions were adsorbed most readily and completely among the three metal ions studied, probably due to the formation of insoluble hydroxides with the hydroxil and silanol groups associated with the calcium silicates. The amount of metals adsorbed was much higher than those taken up by many other natural and synthetic sorbents. For the sorption of anions slower kinetics with respect to metals sorption were observed. $\mathrm{PO}_{4}^{3-}$ was the most readily adsorbed species likely due to the formation of an insoluble salt with $\mathrm{Ca}(\mathrm{II})$ ions on the surface of the sorbent. Under the same experimental conditions $\mathrm{SO}_{4}{ }_{4}$ sorption was not complete and sorption of $\mathrm{CrO}_{4}{ }_{4}^{-}$ions was null since this anion forms only soluble salts with all other constituents present in the studies.

The adsorption equilibrium of the metal ions on nano-structured calcium silicate was examined. The Redlich-Peterson adsorption isotherm matched the experimental results for all metal ions very well. A high adsorption rate of metals onto nano-structured calcium silicate was observed. The experimental results were satisfactorily well explained by applying a pseudo-second-order kinetics model.

\section{ACKNOWLEDGEMENTS}

The financial support of this work under Chile-FONDECYT Project 1100151 is gratefully acknowledged. This study was also partially funded by Program U-Apoya, University of Chile.

\section{REFERENCES}

1. Y. Sharma, C. Weng, J. Hazard. Mater., 142, 449 (2007).

2. M. Matlock, B. Howerton, D. Atwood, Water. Res. 36, 4757 (2002).

3. J. Wu, X. Wang, L. Xiao, S. Song, B. Zhang, Hydrometallurgy 95, 203 (2009)

4. L. Lin, R. Juang, Chem. Eng. J. 112, 211 (2005).

5. D. Cotorás, F. Valenzuela, M. Zarzar, P. Viedma, U.S. Patent 7.479.220,"Plant for the removal of metals by biosorption from mining or industrial effluents" (2009).

6. F. Valenzuela, C. Basualto, J. Sapag, J. Romero, W. Höll, C. Fonseca, C. Araneda., Desalin. Water Treat., 24, 327 (2010).

7. N. Li, Ind. Eng. Chem. Process Res. Dev. 10, 215 (1971).

8. H. Estay, S. Bouquet, J. Romero, J. Sánchez, G. Rios, F. Valenzuela, Chem. Eng. Sci., 62, 5794 (2007).

9. F. Valenzuela, C. Araneda, F. Vargas, C. Basualto, J. Sapag, Chem. Eng. Res. Des., 87, 102 (2009).

10. J. Cortina, N. Miralles, A. Sastre, M. Aguilar, React. Funct. Polym., 32, 221 (1997).

11. S. Dutta, P. Mohapatra, S. Ramnani, S. Sabharwal, A. Das, V. Manchanda, Desalination 232, 234 (2008).

12. H. Modin, K. Persson, A. Andersson, M. van Praagh, J. Hazard. Mater., 189, 749 (2011).

13. T. Bolortamir, R. Egashira, J. Chem. Eng. Jpn., 41, 1003 (2008).

14. E. Basaldella, P. Vázquez, F. Iucolano, D. Caputo, J. Colloid Interface Sci., 313, 574 (2007)

15. W. Carvalho, C. Vignado, J. Fontana, M. Riboldi, Adsorp. Sci, Technol., 25, 673 (2007).

16. M. Alkan, B. Kalay, M. Dogan, O. Demirbas, J. Hazard. Mater., 153, 867 (2008).

17. C. Calderón, M. Franzreb, F. Valenzuela, W. Höll, React. Funct. Polym, 70, 516 (2010).

18. R. Cesaro, M. Fabriccino, R. Lanzetta, A. Mancino, B. Naviglio, M. Parrilli, R. Sartorio, G. Tortora, Water Sci. Technol. 58, 735 (2008).

19. F. Pereira, L. Gurgel, S. De Aquino, L. Gil, J. Environ. Eng., 135, 341 (2009).

20. K. Okada, K. Nishimuta, Y. Kameshima, A. Nakajima, J. Collois Interface Sci., 286, 447 (2005).

21. K. Onishi, T. Nakamura, S. Nishihama, K. Yoshizuka, Ind. Chem. Chem. Res., 49, 6554 (2010).

22. C.Araneda, C. Basualto, J. Sapag, C. Tapia, D. Cotorás, F. Valenzuela, Chem. Eng. Res. Des., 89, 2761 (2011).

23. F. Valenzuela, A. Valdés, V. Ide, C. Basualto, J. Sapag, C. Araneda, Solvent Extr. Ion Exch., 30, 422 (2012).

24. R. Doong, L. Chiang, Water Sci. Technol., 58, 1985 (2008).

25. N. Kabbashi, M. Atieh, A. Al-Mamun, M. Mirghami, M. Alam, N. Yahya, J. Environ. Sci., 21, 539 (2009).

26. S. Huang, D. Chen, J. Hazard. Mater., 163, 174 (2009).

27. Norm, $\mathrm{N}^{\circ} 90 / 2000$, Maximum allowable limits for discharge of liquid wastes to continental and marine surface waters , Minister of GeneralSecretary of Presidence, Chile Government.

28. J.H. Johnston, A.J. McFarlane, T. Borrmann, Patent Application, New 
Zealand, 537747, PCT/NZ2006/000003 (2006).

29. Norm, No4500-SO42-D/1998 and No4500-SO42-E/1998, Standard methods for the examination of water and wastewater.

30. Norm, NCh 2313/15.cR 2009, Phosphate determination in wastewater samples.

31. T. Borrmann, A. J. McFarlane, J. H. Johnston, A. Markwitz, N. Dytlewski, Surf. Interface Anal., 37, 695 (2006).

32. T. Borrmann, J. H. Johnston, A. J. McFarlane, K. J. D. MacKenzie, A. Nukui, Powder Diffraction 23, 204 (2008).
33. M. J. Cairns, T. Borrmann, J. H. Johnston, W. Hoell, Microporous Mesoporous Mater., 95, 126 (2006).

34. C. Fonseca, C. Araneda, M. Yazdani-Pedram, T. Borrmann, C. Basualto, J. Sapag, F. Valenzuela, J. Chil. Chem. Soc. 55, 408 (2010).

35. W. Zheng, X. Li, F. Wang, Q. Yang, P. Deng, G. Zeng, J. Hazard. Mater, 157, 490 (2008)

36. R. Senthilkumar, K. Vijayaraghavan, M. Thilakavathi, P. Iyer, M.Velan, J. Hazard. Mater., 136, 791 (2006).

37. Y.S. Ho, Carbon 42, 2115 (2004).

38. Y.S. Ho, J. Hazard. Mater., 136, 681 (2006) 